\title{
Identifying events that impact self-efficacy in physics learning
}

\author{
Vashti Sawtelle, ${ }^{1}$ Eric Brewe, ${ }^{2,1}$ Renee Michelle Goertzen, ${ }^{1}$ and Laird H. Kramer ${ }^{1}$ \\ ${ }^{1}$ Department of Physics, Florida International University, Miami, Florida 33199, USA \\ ${ }^{2}$ Department of Teaching and Learning, Florida International University, Miami, Florida 33199, USA \\ (Received 9 September 2011; revised manuscript received 4 June 2012; published 28 September 2012)
}

\begin{abstract}
We present a method of analyzing the development of self-efficacy in real time using a framework of self-efficacy opportunities (SEOs). Considerable research has shown a connection between self-efficacy, or the confidence in one's own ability to perform a task, and success in science fields. Traditional methods of investigating the development of self-efficacy have required participants to recollect past events. This reliance on participant memory makes it difficult to understand what impact particular events may have on developing self-efficacy in the moment. We use video recordings of three undergraduate Modeling Instruction students solving a physics problem to characterize SEOs in a moment-by-moment analysis. We then validate these characterizations of the development of self-efficacy by reviewing the problemsolving session with the participants and find evidence that the SEOs identified are taken up and impact self-efficacy. This characterization and validation of SEOs in the moment represents a first step towards establishing a methodology for analyzing the development of self-efficacy in real time.
\end{abstract}

DOI: 10.1103/PhysRevSTPER.8.020111

PACS numbers: 01.40.Fk, 01.40.gf, 01.40.Ha

\section{INTRODUCTION}

In recent years, research interests have focused on how students choose to major in various technical fields, and what motivational factors impact their choice [1-6]. Since the 1980s an abundance of research has shown that science self-efficacy, or confidence in one's own ability to complete the actions necessary to perform a task [7], is related to success in particular fields [8-12], as well as a predictor of the career choice an individual will make [10,13-16]. A few researchers in physics education have also shown a link between physics self-efficacy and success [17-19]. Further, at Florida International University we have found that Modeling Instruction (MI) has a positive impact on self-efficacy [20]. However, few researchers have focused on how self-efficacy develops and how it may be intentionally influenced.

Given that self-efficacy is such an important marker of these success factors, it seems necessary that we as researchers explore its development and characterize the information that contributes to determining self-efficacy, as well as consider interventions that influence the development of self-efficacy. In particular, this paper first completes a literature review on what is known about the development of self-efficacy. Next, this work begins establishing an alternative methodology for investigating how self-efficacy is formed with a focus on real-time events. We demonstrate through a two-phase microanalysis of a problem-solving session that the proposed alternative

Published by the American Physical Society under the terms of the Creative Commons Attribution 3.0 License. Further distribution of this work must maintain attribution to the author(s) and the published article's title, journal citation, and DOI. method yields new information on the development of self-efficacy. Finally, a discussion is presented of how the proposed methodology could be used in combination with more traditional methods to offer a different perspective on how self-efficacy develops in particular contexts.

\section{PREVIOUS RESEARCH ON THE DEVELOPMENT OF SELF-EFFICACY}

Self-efficacy was first developed as an integral part of a theoretical framework attempting to explain how behavioral change takes place [21]. The concept of self-efficacy is defined as the confidence in one's own ability to perform a particular task. Originally, research into using a selfefficacy framework focused on understanding behavior change of individuals with severe phobias [21,22]. Since then, however, self-efficacy has been shown to be a critical component of social cognitive theory $[7,23]$. Social cognitive theory argues that humans use information gained from the world to make decisions about the actions they will take. Self-efficacy, as the confidence in one's own capability, determines the courses of action an individual will pursue. People with high self-efficacy for a particular task will be more likely to choose a path that requires the performance of that task, to persevere in the task over long periods of time, and to persist in the face of difficulties. The utility in understanding the role of self-efficacy in academics lies in the expectation that students with high academic self-efficacy are more likely to succeed in school, to choose career paths that require success in academia, and to choose majors that align with their self-beliefs about personal capabilities.

In particular, researchers have focused attention on science as an area that traditionally has low interest and persistence rates. Studies have shown that self-efficacy is 
able to predict a university student's persistence in science majors as well as science career choices $[9,10,13,14,16]$. Additionally, researchers have found that self-efficacy can predict achievement in science for high school students [24,25] and university students [8-12]. At Florida International University, an hispanic-serving institution in the southeastern United States, we have also found that a student's self-efficacy in physics at the beginning of an introductory physics course predicts the likelihood of a student passing that same course [26]. Further, in our reformed introductory physics classroom centered on Modeling Instruction, we find that students' physics self-efficacy is positively impacted after one semester of the course [20].

\section{A. Sources of self-efficacy}

In order to understand how to positively impact selfefficacy, one must first understand how self-efficacy develops over time. Upon initial reflection on the concept of confidence in one's own ability, it would seem reasonable to conclude that self-efficacy depends on the skills already developed. Thus, we might expect that if the skills to complete a task are present, then the individual would necessarily have a high self-efficacy to execute the action. However, Schwartz and Gottman [27] have shown that even when people have the full set of skills and knowledge to perform a task, they can still feel incapable. Bandura [7] contended that this is because confidence in ability does not rely directly on the number of skills, but on what an individual believes they can do in a particular circumstance. Bandura postulated that individuals derive selfefficacy information from experiences that focus on actually using these skills. Bandura [7] posited, and Lent et al. confirmed [28] that these experiential sources of information can be broken into four categories: personal mastery experiences, vicarious learning experiences, social persuasion experiences, and an individual's physiological state. Bandura [7] described each source of selfefficacy as serving a different role in the development of self-efficacy. However, he noted that disentangling the role each source plays may be difficult when examining the self-efficacy of an individual, as the development of selfefficacy through each source may not be inseparable.

While considerable research has been done investigating the relationship of self-efficacy to success, persistence, and career choice, fewer investigators have studied the development of self-efficacy. Within this smaller body of literature, much of the research focuses on confirming the relationship between the four experiential sources and self-efficacy itself [24,28-32]. The goal of this research is often to confirm or deny Bandura's hypothesis that personal accomplishments in the form of mastery experiences play the primary role in an individual evaluating their capability. Researchers have also tried to determine if factors such as gender or particular tasks change the types of experiences drawn upon in judging self-efficacy $[24,31,32]$. Regardless of the focus, the majority of the research takes place by developing quantitative surveys that use researcher-derived experiences as stand-ins for the theoretically posited sources of self-efficacy [28,31-35]. The limitation with these methods is that they do not leave room for researchers to uncover additional factors that people may draw on when judging capability. With this in mind, a few researchers have turned to qualitative data collection methods [28,29,36-39]. These methods, ranging from factor listing to semistructured interviews, have revealed interesting ideas about self-efficacy and how the dependence on each of the individual sources varies across individuals, particularly for those of different genders. The following sections outline the research that has been done on the contribution of each experiential source to selfefficacy, as well as propose an alternative way of investigating the development of self-efficacy.

\section{Mastery experiences: Personal attainments or failures}

Bandura [7] described enactive mastery experiences as being the primary indicator of confidence in capability. He theorized that these mastery experiences, experiences with previous personal attainments or failures in a task similar to the one at hand, had the most influence over an individual's confidence in their ability because they provide authentic evidence as to whether the individual is capable to succeed at the task. Many researchers studying the influence of mastery experiences have found evidence to support Bandura's conjecture that these experiences have the greatest sway for determining self-efficacy [40]. In her quantitative 2008 study of the self-efficacy of high school students in various science courses [24], Britner found mastery experiences played a critical role in determining self-efficacy. In the study, students were asked to answer a survey about their confidence to succeed in their science course as well as to rate the types of experiences they had in the past. Britner found mastery experiences were the only significant predictor of self-efficacy across all the fields of science for boys. Similarly, Matsui, Matsui, and Ohnishi [32] found past grades in mathematics course (which they described as a mastery experience) account for the largest variance in predicting the mathematics selfefficacy of Japanese students in high school math classes.

Results from some qualitative studies also support the claim that mastery experiences are the most influential. In 1996, Lent et al. completed a study asking university students, enrolled in an introductory psychology course, to rate their confidence in their ability to pass particular math classes with a grade of B or higher [30]. Once this task was completed, the researchers asked the students to reflect on the information they used to rate their capability. The students were asked to make a list up to 10 of these factors, from which they then identified the most influential factors. Upon analysis, Lent et al. found that experiences 
that could be classified as mastery experiences were predominate in the lists the students made. In 2006, Hutchison et al. completed a study using similar methodology, again employing the factor-listing technique [29]. This time the course in question was an introductory engineering course, and all of the students in the study were currently enrolled in the course at the time of the study. Hutchison et al. also found that most of the factors that first-year engineering students listed as influencing their confidence in ability to succeed in an introductory engineering course could be categorized as mastery experiences.

In interview studies, the influence of mastery experiences became more mixed. In 2008, Hutchison et al. did a follow-up interview study with students enrolled in the same introductory engineering course in which the factor-listing task was completed [36]. The students were interviewed twice: once three weeks into the course and a second time halfway through the course. In this follow-up study, the researchers found that before any of the students had the course, their self-efficacy for succeeding in the engineering course came almost entirely from mastery experiences. However, when students were interviewed midsemester, students described performance comparisons (vicarious learning) in abundance, rather than performance experiences. In addition, Zeldin, Britner, and Pajares [39] completed an interview-based qualitative study, with findings indicating that the influence of mastery experience depends on gender. In this work, the researchers interviewed women and men who have successful careers in science or mathematics. The researchers asked the participants questions designed to elicit thoughts about significant events that had an influence on them throughout their career. The results suggested that mastery experiences are the primary influences on the male participants, but are not the most influential for the women in the study.

Overall, these studies suggest that when evaluating experiences quantitatively mastery experiences appear as a dominant predictor of overall self-efficacy. However, results have also demonstrated that when completing in-depth interviews, the impact of mastery experiences is less clear. Mastery experiences have been shown to be an influential source for students when recalling their experiences on paper, but when the students are interviewed the connection between self-efficacy and personal mastery experiences becomes less clear.

\section{Vicarious learning: Observing others performing a task}

The distinguishing feature of vicarious learning experiences is the observation of another person performing a task. Vicarious learning experiences can take two distinct forms: (1) modeling, when an individual sees a person similar to oneself perform a task [7], and (2) performance comparison, when an individual's focus is on determining how much better or worse one's own performance was compared to another's performance [36]. Usher and
Pajares [40] point out that performance comparisons are particularly relevant in academic settings, as in most academic settings there is not an absolute measure of what success means. As a result, students judge their performance based on what others are doing. In terms of observation experiences, the impact of the model on selfefficacy depends on a few factors: how similar the individual sees the model to be like themselves, whether the model demonstrates a coping mechanism (struggling through problems) or a mastery model (successful completion of the task), and how competent the model is at performing the task $[7,40]$.

In Bandura's theory of the influence of vicarious learning on self-efficacy, he contends that peers would have a greater influence on self-efficacy than adults for students [7]. However, few researchers have investigated this claim. One study investigating the independent factors that contribute to self-efficacy did consider the effect of splitting peer modeling from adult modeling [30], and found that peer modeling appeared as a distinct factor in the factor analysis, and had a stronger relationship to the measured self-efficacy than did the adult modeling factor. Most other studies investigating the influence of vicarious learning experiences on self-efficacy have not distinguished between peer models and adult models. It is possible that the low to modest reliability coefficients for the vicarious learning factor on several quantitative self-efficacy surveys are a result of not distinguishing between the types of model [31-35].

The difficulty in measuring the vicarious learning source of self-efficacy may also be reflected in conflicting results from various studies on its predictive relationship with self-efficacy. Several quantitative survey design studies have identified vicarious learning experiences as the source that is least likely to predict self-efficacy [31,33,41]. Vicarious learning experiences were not referenced as a primary influence on determining individual's selfefficacy in factor-listing studies either [29,30]. However, studies focusing on nonmajority students, such as students of South Asian descent in Canada [42] and African American middle school students in the United States [35], have found that vicarious learning experiences have a significant relationship to self-efficacy.

Additionally, in qualitative interview investigations, vicarious learning experiences seem to play an important role in distinguishing the development of self-efficacy for men and women. Investigating the development of selfefficacy for women in science and mathematics careers, Zeldin and Pajares [38] found that women primarily described interactions with others and often referenced the vicarious experiences these interactions provided when reflecting on how their confidence in capability developed over time. Additionally, in an interview study of the longitudinal development of self-efficacy in an introductory engineering class, Hutchison et al. [36] found 
that a distinguishing factor between men and women was the type of vicarious experience they recalled throughout the engineering class. These researchers found that while we might expect women and men to have the same types of experiences, men were likely to reflect on comparison or modeling experiences that were positive for building confidence, while women were more likely to describe experiences that would have a negative influence on their confidence in capability.

In general, vicarious learning experiences appear difficult to measure, yielding low reliability measurements and conflicting results in the source's predictive ability for selfefficacy. However, the results of some studies suggest that vicarious learning experiences may play a key role in differentiating the development of self-efficacy for students of various ethnic backgrounds, or when investigating the self-efficacy of men and women.

\section{Social persuasion: Messages received about ability}

The primary definition of social persuasion experiences focuses on the messages an individual receives from others about their ability to perform a task. When Bandura [7] defined social persuasion experiences as a source of self-efficacy, he primarily focused on the experience of receiving evaluative feedback on a performance. Bandura discussed how individuals cannot rely solely on themselves to provide self-evaluation because it requires knowledge of which they might only have a limited amount. Instead, individuals rely on others deemed credible to provide evaluative feedback needed to judge performance capabilities. However, Bandura maintained that these messages are not always conveyed verbally. Rather, social evaluations of competence are often conveyed indirectly and may be communicated through social practices or indirect commentary. In their review of the sources of self-efficacy literature, Usher and Pajares [40] noted that many studies have investigated the social persuasion influence by focusing primarily on the encouraging messages students perceive from their peers, teachers, and parents. While these investigations are in line with Bandura's theory of how social persuasion experiences work to influence selfefficacy, it is notable that most researchers do not examine the messages sent to students from the larger culture, negative messages that might be conveyed, or consider how those messages might be conveyed without verbal encouragement.

In both the qualitative and quantitative literature, social persuasion experiences take a prominent role when the development of self-efficacy beliefs for women and men are compared. In an investigation by Zeldin and Pajares [38] into the development of self-efficacy for women in science and math careers, it was found that women more often recalled social persuasion experiences than they did mastery experiences. When the men spoke of social persuasion experiences it was in a dispassionate manner, which contrasted starkly with the discussions from women in the earlier study [39].

Results from other studies, both quantitative and qualitative, are mixed in supporting the findings of Zeldin et al. In Britner's 2008 study on the self-efficacy of high school students in science classes [24], she found that social persuasion had the strongest effect on self-efficacy for girls in life sciences courses. However, she also found that the social persuasion source did not significantly predict the self-efficacy of girls in physical science classes. Additionally, in factor-listing studies, neither men nor women listed social persuasion experiences as a primary influence in determining self-efficacy in engineering or mathematics $[29,30]$.

In addition to gender differences, the contribution of social persuasion experiences to self-efficacy may vary with cultural background. In a 2004 study, the mathematics self-efficacy beliefs of South Asian immigrant students in Canada derived more from vicarious learning influences and social persuasion experiences than did their White counterparts [42]. Similarly, Usher and Pajares [35] found that for African American middle school students in the United States social persuasion experiences accounted for the most variance in predicting their academic self-efficacy, while all four of the sources predicted the self-efficacy of White students.

Overall, a similar picture develops for the literature on social persuasion experiences as the one that was discussed for vicarious learning experiences. The social persuasion source of self-efficacy appears to often be inadequately probed in quantitative surveys as they do not address the indirect messages communicated by society. Further, when studies consider different ethnic groups, results vary as to which source predicts the self-efficacy of students.

\section{Physiological state: Emotions mediate other sources}

Bandura [7] defined the physiological state source of self-efficacy as the somatic information individuals rely on when evaluating their capability to perform a task. Individuals may interpret stress in a particular situation as an indicator that they are not capable, or a feeling of strength or stamina as an indicator of capability. In the literature, however, researchers have primarily focused on the effect of anxiety on self-efficacy with little attention to the more positive physiological states that may influence an individual's confidence in capability [40]. Even within this limited investigation, results measuring the relationship between anxiety state and self-efficacy have been mixed [40]. On the other hand, math anxiety has been found to reliably predict math self-efficacy $[31,43]$, but not with as strong a prediction as the other three sources of self-efficacy. These varying results may be because anxiety is not truly a complete representation of the physiological state source of self-efficacy as it does not address any of the positive impacts this source may have on self-efficacy. 
Qualitative research has addressed the physiological state source minimally. Both the factor-listing tasks from Lent et al. [30] and Hutchison et al. [29] mentioned findings related to the physiological state, but in neither study did it take a prominent role in determining self-efficacy. The lack of physiological state in the qualitative literature may be a result of the difficulty in assessing this source. Bandura [7] contended that activities are often surrounded by a number of situational variables that may carry emotional information. Further, each of these emotional reactions carry different messages to different individuals. For example, a particular individual may interpret nervousness before giving a public presentation as a sign of incompetence, but another may identify it as a sign of the adrenaline rush necessary to project their voice loudly and clearly. Couple this with the idea that preexisting self-efficacy beliefs will affect how an individual processes somatic information, and we see that the physiological state may be viewed as a coeffect with the other three sources of selfefficacy $[7,44]$. This interpretation implies that disentangling the effect of physiological state from the other source variables may be difficult, particularly in qualitative work. As such, we do not consider physiological state in our analysis, and instead focus our attention on interpreting and understanding the other three sources of self-efficacy.

\section{B. Alternative approach to investigating the sources of self-efficacy}

While researchers have used a variety of methods to understand the development of self-efficacy, many of the studies into the sources of self-efficacy have approached the question from the same direction. The majority of studies have used quantitative surveys in which researchers create items that they believe will elicit the correct type of capability information to be classified under one of the four sources of self-efficacy. Qualitative studies that have been completed focus on interviewing participants about their beliefs in their capabilities and then coding their responses by the types of experiences they describe, with a middle ground factorlisting type of research filling the continuum between quantitative and qualitative studies. While these methods are varied, there is a common element to all of these studies: they focus on eliciting past experiences from the participants.

These studies, both quantitative and qualitative, have revealed how the hypothesized sources influence confidence in capability, as well as the additional factors and subtle differences between the theoretically derived sources of self-efficacy. However, in relying on participants to reflect on their past, these studies ask participants to both accurately recall the information they used to influence their decision about capability and to accurately represent all the details of an event that influenced the judgment of their capability. In [7], Bandura noted that the way an individual recalls an event is most likely not an accurate reproduction of the event. He went on to say that what is important in developing self-efficacy, then, is not the event itself but the way an individual interprets it. This presents a difficulty, however, for those who would like to influence the way self-efficacy develops in the moment. How can we create experiences that will increase selfefficacy if we cannot be sure of the way the event will be interpreted? What happens that makes us recall an event in a particular way? What things are individuals in these interview studies not mentioning when they weigh information to determine their capability? And how do these things that are not mentioned or not recalled influence the way our self-efficacy develops?

It is with these types of questions in mind that our research has taken a different perspective on characterizing the way self-efficacy develops. We approach the question by attempting to characterize experiences that have the potential to influence reasoning about one's capability in the future. We do not claim that these events will indeed be recalled in future analyses of self-efficacy. However, in focusing on experiences that present the opportunity to build self-efficacy, we may be able to see how particular actions or events influence self-efficacy development in a way that we could not see if we relied on people reflecting on their past. To this end, this paper begins the discussion of characterizing experiences as self-efficacy opportunities (SEOs). This work primarily focuses on a moment-bymoment analysis, connecting these detailed descriptions to the particular types of experiences that students think about when judging their self-efficacy. This paper also validates these SEOs by demonstrating that some are taken up and directly influence confidence in ability.

\section{METHODS}

The goal of this study is to begin to understand how opportunities to influence self-efficacy unfold in a moment in time. We have a working assumption that self-efficacy is influenced through the theoretically posited sources of selfefficacy. Our research question focuses on how these experiences take shape as moments unfold. To this end, we used a microanalytic lens [45] which focuses attention on the how of human interaction [46]. Our study evolves in two parts. In the first, we microanalyze three participants participating in a problem-solving session for evidence of selfefficacy experience opportunities. In order to verify that these opportunities do indeed represent events that have the potential to influence self-efficacy, we follow this phase with a set of individual post hoc interviews with the participants. We analyze the post hoc interviews for evidence that the SEOs we identified occurring in the problem-solving session are sometimes taken up and influence self-efficacy.

\section{A. Modeling Instruction classroom as a context for this study}

A key motivation for this study was to understand the successes in the Modeling Instruction (MI) classroom. The 
Physics Education Research Group at Florida International University (FIU) has focused on increasing the number of historically underrepresented groups in physics primarily through reforming the introductory physics classroom to feature Modeling Instruction. Modeling Instruction is a reform effort that has had great success in improving student conceptual gains [47], as measured by the Force Concept Inventory [48], as well as improved retention rates [47] and favorable attitudes toward learning physics [49]. The development of MI was guided by the Modeling Theory of Science [50], which focuses on the process of building, validating, and deploying scientific models. The implementation of MI is designed to give students an authentic scientific experience as well as to make the nature of science a coherent theme across content and pedagogy. Key elements to accomplishing these goals include (1) a focus on robust model development and deployment to describe physical phenomena [51], (2) a collaborative, student-centered environment [52], as well as (3) large group consensus-building discourse [53].

At FIU, MI operates in a collaborative environment with 30 students in a studio-format class with integrated lab and lecture. Inquiry labs and activities are focused on conceptual reasoning and modeling physical phenomena. Students working in small groups on these activities are the primary way models in the classroom are built, validated, and deployed. This paper focuses on one element of the MI classroom design: describing physical phenomena through the use of student-developed and student-deployed models. Previous research at this institution has shown that MI improves self-efficacy over the course of a semester, as measured by a quantitative scale [20]. One motivation for this study is to understand the mechanism for how MI has impacted self-efficacy over time. With this motivation in mind, we attempt to characterize the ways that self-efficacy could potentially be impacted over time during an activity that mimics those that occur in the MI classroom.

Beyond the initial motivation for this study, the MI course provides an ideal context for understanding the development of self-efficacy. Previous work indicates the MI has an impact on self-efficacy development [20], and we expect that a qualitative investigation would yield information on how that self-efficacy develops. Through emphasizing peer interactions and student-led model building, it is expected that students will provide substantive feedback to one another on the progress of problem solving. Accordingly, we expect that students from a MI environment will provide rich data for understanding sources of self-efficacy that rely on direct interactions (vicarious learning experiences and social persuasion experiences).

\section{B. Participants}

Participants in this study were three students from a MI class, Lisa, Gina, and Jessica (all pseudonyms), who were familiar with working with one another. All three of the participants were women enrolled in the same introductory physics MI class during the semester they participated in the problem-solving portion of this study. Further, all three are part of a small cohort within the university system, are premedical biology majors, and are in their junior year of college. Lisa and Gina are identical twin sisters, and Jessica is both a friend and a colleague. Neither Lisa nor Gina had any experience with physics prior to the MI course. Jessica had taken physics in high school, but in later interviews expressed the view that she had still valued what she had learned in the MI course. All three women volunteered for the study, and they were paid for their time.

The sampling in this study was a purposeful sample, rather than a representative one. The three participants in this study were chosen, in part, due to the close working relationship they had already established through prior experiences. In looking for evidence of moment-bymoment opportunities to impact self-efficacy, we chose participants who we expected to intensify the phenomenon in question [54]. By choosing three students who share similar characteristics and common experiences, and indeed identical twin sisters exemplify this similarity, we increased the probability that they would see one another as peers, thus providing insight into vicarious learning experiences. Including participants that are familiar with one another also increases the likelihood that the students would be comfortable working with and evaluating one another, thus providing opportunities for insight to mastery experiences and social persuasion experiences.

\section{Data collection and analytic framework}

As described above, the data collection in this study took place in two distinct phases. The first, the problem-solving session, was a videotaped session in which the three participants worked together to model a physical phenomenon. The second, the post hoc sessions, were three individual sessions in which the original problem-solving participants viewed themselves on video and expressed feelings and opinions about how the events influenced their self-efficacy.

\section{Problem-solving session}

Lisa, Gina, and Jessica participated in four problemsolving research sessions over the course of the first four weeks of the semester. The first session was designed to get the students comfortable with solving a problem together in front of a camera. The first author was present during each session and introduced the activities that took place during the session. The session took place in a room adjacent to the participants' classroom that had a large table and set of whiteboards and were videotaped. The three women were given a problem, chosen by their instructor to be similar to those given in their MI classroom, and were instructed to spend 45 minutes working on the task. The problem was designed to be just beyond what the 
students had learned in class. In this way, the expectation of the researchers was that the students would need to work together to move forward in the problem-solving process. The participants were asked to talk aloud as they worked on the problem, focusing on why and what they were doing. This paper includes the microanalysis of a 1-minute segment from the second session ( 2 weeks into the semester), which focused on modeling a one-dimensional, constant acceleration situation as seen in Fig. 1.

The expected outcome of modeling this physical situation includes creating and reasoning with internally coherent position-time, velocity-time, and acceleration-time graphs as well as a pictorial representation, motion map, and possibly an algebraic solution for the time and position when the car and truck would meet. An example of an acceptable solution is shown in Fig. 2. The participants were familiar with this type of question, as well as the expected outcomes, from the MI classroom.

Our research focus on characterizing in-the-moment opportunities to influence self-efficacy requires attention to detail beyond the substance of the talk between the participants; it also requires attention to the way in which ideas are communicated. Attending to the ways participants communicate with one another means focusing on the talk between participants, as well as the gestures and body language they use to communicate. Erickson's microanalysis of interaction [45], which aims to describe processes that produce particular outcomes in great detail, allows us to focus our attention on the various messages the participants may be communicating. In this case we describe events that unfold in an instance of physics problem solving through the lens of self-efficacy building experiences.

To begin the microanalysis process, we followed the recommendations of Erickson [45] by choosing a series of events to focus the analysis. The events we chose were based on the modeling process the students were working through (i.e., introduction and representation or coordination of representations) [51]. We identified moments in the video that exemplified each step of the modeling process, which we established as the focal event for analysis. Only then, as suggested by Erickson [45], did we begin the process of determining the boundaries of that event (i.e., the beginning and end of the event). For example, the data discussed in this paper are taken from an 8.5-minute episode in which the students are engaged in constructing a coherent set of position-time, velocity-time, and acceleration-time graphs. The focal event in this process involved using the velocity-time graph to construct a position-time graph. Other steps of the modeling process

A car, initially at rest, accelerates toward the west at $2.0 \mathrm{~m} / \mathrm{s}^{2}$. At the same time that the car starts moving, a truck, $350 \mathrm{~m}$ west of the car and moving at $16 \mathrm{~m} / \mathrm{s}$ toward the east, starts to slow down, accelerating at $1.0 \mathrm{~m} / \mathrm{s}^{2}$. The car and truck pass safely.

FIG. 1. Situation given to the participants during the problem-solving session.

(a) Motion Maps:

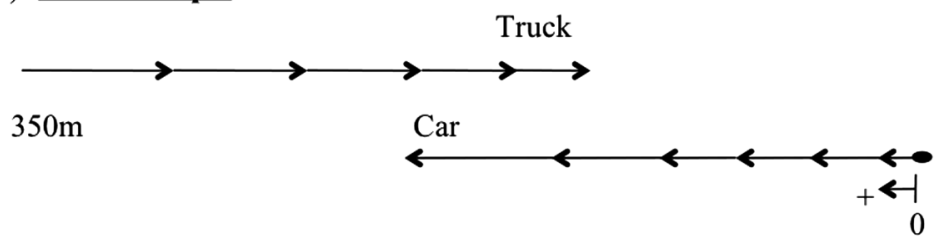

0 (d)

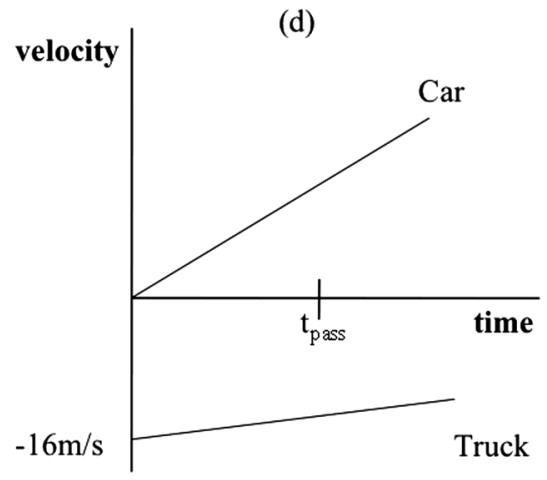

(b) Assumptions:

- Acceleration of both car and truck is constant

- West is the positive direction

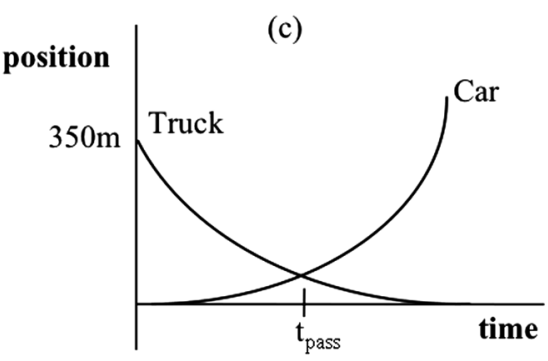
. 
with additional focal events included defining assumptions and writing an algebraic expression for the position of the car. Identifying the boundaries of the focal event for analysis defines the next step of the microanalytic process. Defining the clip boundaries is an iterative process that involves examining in close detail the focus of the interaction and looking for the beginning and end points of the process [55].

Next, we transcribed the event, taking care to note particular nonverbal actions that may contribute to our theoretical frame [46]. The transcript we present here places emphasis on the nonverbal behaviors [56] that impact self-efficacy such as head nods and gaze direction. Finally, we analyzed the transcript and video looking for short snippets of interactions that could be classified as self-efficacy opportunities. This stage required several viewings of the event in order to describe and identify opportunities for the various sources of self-efficacy to be taken up for each of the three participants involved. The process of defining these self-efficacy opportunities is described in Sec. IV.

\section{Post hoc interviews}

After the initial analysis of the student problem-solving sessions, the researchers determined that leading a stimulated recall interview session with the participants would add insight to the interpretations of the events. However, the students at the time of the first session were enrolled in the first half of a year-long course together. We chose to interview the students a year after the initial problemsolving interview. This mean that the students had completed the full year of introductory physics and were no longer interacting with their professors on a regular basis. We hoped that this would allow them to reflect on the problem-solving interview with the perspective of someone who had completed their physics learning; this also more closely replicates the reflection that happens in other self-efficacy measures. Lisa, Gina, and Jessica each participated in individual post hoc interviews one year after the problem-solving sessions were completed. The interviews were designed to focus on the videos taken of the problem-solving session. After a few questions regarding their overall experience in the Modeling Instruction physics class, each participant individually watched the same segment, 8.5 minutes long, of the second problem-solving session chosen and transcribed by the first author. The segment was chosen because it focused on material that was central to the class and was positioned within the first several minutes of the longer 45-minute problem-solving interview. It was expected that positioning the segment in this way would allow the participants to easily recall the process they had been going through, as they could watch the early development of the ideas in the session.

Each participant was asked if there was any portion of the segment that stood out to her. After the participant- identified segments were discussed, the interviewer went through six 30-second clips that had been chosen prior to the interview. We present the microanalysis of one episode that consists of two of these sequential clips in this paper. Two of the clips not presented here, as well as the additional video, were included at the beginning of the interview in order to achieve a comfort level from the participants, as embarrassment is a top concern when dealing with video recordings [45]. Each of the clips was chosen because the researchers had previously identified at least one self-efficacy opportunity for each of the participants within each clip. In the interview each participant was asked to watch each clip twice. In the first viewing they were asked to focus on themselves and to share thoughts about what they were feeling and how the event impacted them. In the second viewing the participant was asked to focus on the other two women in the problemsolving session and again to discuss what they saw happening and how it may have impacted each of the women in the room. The participants were not briefed on issues of self-efficacy, and as a result were only expected to discuss their thoughts and feelings after watching the video.

These post hoc interviews were analyzed for evidence that the participant's self-efficacy was impacted by the event in the problem-solving session. We used the post hoc interviews to investigate the salience and impact of the opportunities we identified on the students' confidence in their ability to proceed with the problem-solving process, but not to confirm or disprove the presence of the self-efficacy opportunities in the moment. Within the students' descriptions of their feelings about the video clips, researchers looked for evidence of changing self-efficacy. Then the corresponding moment was cross-referenced with the originally analyzed problem-solving session to look for validity of self-efficacy opportunities being taken up and impacting self-efficacy.

\section{Reliability and validity}

In order to maintain reliability of our interpretations in the data analysis, several measures of validity were performed in the data collection and analysis. First, the data collection and design of the problem-solving sessions were discussed and designed by several researchers. Additionally, researcher reflexivity [57] was established through the use of a researcher reflection notebook, a method used for researchers to monitor their subjectivity during data collection and analysis. Reliability during the microanalytic process was achieved through a combination of peer debriefing [57], and through triangulation of both the microanalysis of the problem-solving process and the post hoc interviews. Peer debriefing primarily took place as a meeting between the first and third authors of this paper, where the first author would bring clips of video identified as evidence of a particular SEO and the third author would challenge the assumptions behind this process, make arguments opposing the identification of 
the SEO in order to test the strength of the argument, and push the first author to the next step methodologically [57]. This type of peer debriefing happened weekly throughout the analytic process and was combined with additional meetings of a larger video-watching group made of physics education researchers who challenged the methods and interpretations of the data. Additionally, though only $1 \mathrm{~min}$ ute of data analysis is presented in this paper, an additional 30 minutes of data were microanalyzed in an effort to be sure that the episode is representative of the interactions seen in the problem-solving sessions [45].

\section{RESULTS}

As described in Sec. III, we approached this work through a two-phase analysis process: a microanalysis characterizing self-efficacy opportunities of a short segment of video from the problem-solving sessions, followed by an analysis of the portion of the post hoc interviews that focused on the same segment of video for evidence of the SEOs being taken up by the participants and impacting self-efficacy. We present the results of this analysis in a similar manner within each source of self-efficacy, first identifying SEOs and following with a discussion of evidence from post hoc interviews that the SEOs were taken up.

The 1-minute segment we microanalyzed is a portion of the larger problem-solving session and focuses on Lisa, Gina, and Jessica attempting to build and reason with internally coherent position-time, velocity-time, and acceleration-time kinematic graphs to model the situation. We chose this segment to focus the discussion because there is abundant activity and interaction between the students. Just before this episode the three women decided that they can assume the acceleration of both the car and truck are constant, which is appropriate in this situation. In the transcript presented in Table I they focus on trying to represent the velocity of the car. The episode ends with the women transitioning to trying to find the change in position by using the velocity graph they have just drawn. In the transcript, time increases downward along the vertical axis and columns represent the behaviors of the different participants. The nonverbal and verbal behaviors are separated within each column in order to highlight the nonverbal action from the participants [56]. The superscripts denote the order of behaviors, where behaviors marked with the same superscripts occurred at the same time. To get a flow of the conversation, a reader could follow the bolded verbal utterances from top to bottom of the transcript.

In this episode we see the participants working to draw the shape of the velocity-time curve. They begin with Gina proposing a curved line for the velocity-time graph (turn 2), and then two possible straight lines with different slopes (turns 9 and 10). Jessica and Lisa work together, checking that the proposed velocity-time graph is consistent with the horizontal line they have drawn for the acceleration-time graph (turns 18-22). At the end of the episode we see Gina attempting to use the velocity information to find displacement using the area under the velocity-time graph (turns 26-31).

We present the descriptive analysis of this segment by the various self-efficacy opportunities (SEOs) that are present during the problem-solving session, followed by evidence from the post hoc interviews demonstrating that SEOs are being taken up and impacting the self-efficacy of the students. We break the analysis into the three types of opportunities for self-efficacy [vicarious learning opportunities (VLOs), social persuasion opportunities (SPOs), mastery experience opportunities (MEOs)], and thus present the analysis of some of the same events under multiple headings. Table II provides a set of touchstone examples of each of the types of self-efficacy opportunities for reference. By combining the well-researched characterizations of selfefficacy experiences from the past-tense perspective with characterizations of opportunities for self-efficacy experiences in the present-tense situation, we aim to provide researchers and educators with a way to construct events that can be hypothesized to impact self-efficacy.

\section{A. Vicarious learning opportunities}

\section{Identifying and characterizing vicarious learning opportunities}

Vicarious learning opportunities (VLOs) can be difficult to identify, as we require evidence that one individual is performing a task and that another person is paying attention to the performance of that task (see Table II for reference). This process of a model performing a task and an observer tuning to the model's task performance requires the analysis of two distinct roles: the modeler and the observer. In characterizing VLOs, then, we require some evidence that the observer is cognizant of the performance. This evidence may come from signals such as a verbal affirmation or a gesture like a nod or shake of the head. When we turn to analyzing turns $1-25$ for evidence of VLOs, we see several unfolding in the first several lines.

In turns $1-5$ we see a VLO when Gina, in the role of model, attempts to draw a curved line for the velocity-time graph. As she draws the line, she turns to look at Jessica, who serves as the observer, and Jessica responds by shaking her head, indicating no. In this interaction we see Gina first performing the task of drawing a representation of the velocity from the acceleration graph, and we see evidence that Jessica is watching this task performed through her disagreement with what Gina drew. Gina's demonstration of the task provides a vicarious learning opportunity for Jessica that she may reflect upon later to influence her selfefficacy for representing velocity-time graphs.

Immediately following this interaction, Gina again turns to the board, as the model in the situation, and draws two straight lines for the velocity graph, one above the $x$ axis with a positive slope and the other below the $x$ axis with a 
TABLE I. Transcript of a segment of the problem-solving session. The columns separate nonverbal and verbal behaviors for Gina, Jessica, and Lisa. The numbers denote the order of behaviors.

\begin{tabular}{lccccccc}
\hline \hline & Gina & & Jessica & & \\
Nonverbal & & Verbal & Nonverbal & Verbal & Nonverbal \\
\hline
\end{tabular}

1 Turns to her right, to look

1 And then

at Lisa. Points at the line on

this is positive.

the acceleration graph

2 Moves her hand to the velocity

2 The velocity would

graph above the acceleration

somehow be this?

graph. Draws a curved line.

3 looks slightly to her left at Jessica.

\section{Agree?}

4 Shakes her head slightly

5 Mimes a positive slope

line twice with her index

5 It would be more

like this.

6 Erases the arc she drew as she turns back to face the board.

6 It would be oh, a line. Yeah, a line.

7 Takes a step to her

\section{That would}

left and out of the view of be position.

the camera. Draws an arc in

the air with her index finger.

\section{So it could be \\ like this...}

10 ...or like this

10 Draws a negative slope line below the $x$ axis.

11 Turns her head slightly to

the left to look at Jessica.

12 Takes a step back from the board,

and brings her right hand to her chin.

13 Turns to the right to look at Lisa.

\section{Right?}

13 That's the problem
8 Nods. Returns to the origin of we had in class.

15 Takes a step to her right 


\begin{tabular}{|c|c|c|c|c|c|}
\hline \multicolumn{2}{|c|}{ Gina } & \multicolumn{2}{|c|}{ Jessica } & \multicolumn{2}{|c|}{ Lisa } \\
\hline Nonverbal & Verbal & Nonverbal & Verbal & Nonverbal & Verbal \\
\hline
\end{tabular}

18 Turns back to face the board.

18 Raises her right hand to point at the negative slope

18 The slopes line on the velocity graph.
18 Takes a big step to her left, and points with her right hand at the positive slope line on the velocity graph.

19 Points at the negative 19 Yeah, the slope slope line on the velocity graph. of this is negative, 20 Points at the horizontal 20 so this line on the acceleration graph

21 points at the space below the $x$ axis on the acceleration graph.

22 Takes a step back away from the board.
18 No, because

f velocity

is. . .increasing

22 Takes a step forward and

using her right index finger erases

the negative slope line on

the velocity graph.

23 Using the marker, but making no mark on the board, draws in

23 But it would be like...this. .

\section{4 no, we're}

assuming.

the velocity graph.

25 Redraws the positive slope line above the $x$ axis on the velocity graph

26 Takes a step back, then forward

26 And then to

again and poises the marker to write in

the empty space beside the velocity graph.

27 Makes several up and down motions 27 ..to get the. .

with her right index finger (shading in) in this area,

the region between the positive slope line

and the $\mathrm{x}$-axis on the velocity graph. 


\begin{tabular}{|c|c|c|c|c|c|}
\hline \multirow[b]{2}{*}{ Nonverbal } & \multirow[b]{2}{*}{ Verbal } & \multicolumn{2}{|c|}{ Jessica } & \multicolumn{2}{|c|}{ Lisa } \\
\hline & & Nonverbal & Verbal & Nonverbal & Verbal \\
\hline $\begin{array}{l}28 \text { Turns her shoulders and head to } \\
\text { the right to look at Lisa }\end{array}$ & $\begin{array}{l}28 \text { What was the } \\
\text { equation? }\end{array}$ & & & & \\
\hline $\begin{array}{l}29 \text { Takes a step backward, still looking } \\
\text { over her right shoulder, to stand beside } \\
\text { Lisa. Looks at the paper Lisa is } \\
\text { holding in her hand. }\end{array}$ & & & & $\begin{array}{l}29 \text { Looking towards } \\
\text { the board. }\end{array}$ & 29 It's a triangle. \\
\hline \multirow[t]{3}{*}{$\begin{array}{l}30 \text { Takes a step forward to the board, } \\
\text { and writes delta }\end{array}$} & $\begin{array}{l}30 \text { Yeah, but it's } \\
\text { change in... }\end{array}$ & & 30 Velocity? & & \\
\hline & 31 & & & $\begin{array}{l}31 \text { Moves her head (only) } \\
\text { back and then forward } \\
\text { quickly, raises her eyebrows } \\
\text { and purses her lips. }\end{array}$ & \\
\hline & & & & $\begin{array}{l}32 \text { Takes a step backward } \\
\text { and brings her left hand } \\
\text { up to hold the papers. }\end{array}$ & $\begin{array}{l}32 \text { She's confusing } \\
\text { herself. }\end{array}$ \\
\hline $\begin{array}{l}33 \text { Takes a step backwards next to Lisa, } \\
\text { looking over her right shoulder at Lisa. }\end{array}$ & $\begin{array}{l}33 \text { What's the equation } \\
\text { for displacement? }\end{array}$ & & & & \\
\hline
\end{tabular}


TABLE II. Touchstone examples of self-efficacy opportunities.

\begin{tabular}{ll}
\hline \hline Self-efficacy opportunity (SEO) & \multicolumn{1}{c}{ Example } \\
\hline Vicarious learning opportunity (VLO) & $\begin{array}{l}\text { Vicki watches from the back of the classroom as Andy solves a problem on } \\
\text { the board. When Andy's mistake is pointed out, Vicki realizes that she could } \\
\text { have made the same mistake. } \\
\text { Michael is working with a group of students to create a presentation on a } \\
\text { whiteboard. He turns to his partner, Cindy, to ask if he wrote the equation correctly. } \\
\text { Cindy interprets Michael's request for her evaluation as confidence in her knowing } \\
\text { the correct expression. } \\
\text { Andy solves a problem in the front of the classroom. Other students in the class point } \\
\text { out that a mistake was made in the presentation. }\end{array}$ \\
\hline \hline
\end{tabular}

negative slope (turns 9-11). In the next couple of turns we see that she both looks at Jessica and turns toward Lisa. They both respond to her drawing, indicating observation of the task, by talking about the slope of the line (turns 18-22). Again, this provides a vicarious learning opportunity for Lisa and Jessica as they may recall Gina's uncertainty about which line is correct and later judge their own competence accordingly.

Alternatively, we may also view this entire sequence (turns 1-22) as a VLO for Gina. In turns 18-21, Lisa, serving as the model, reasons aloud why only one of the lines could be correct based on the information about the slope of the line. Gina, the observer in this case, watches as Lisa reasons through this, and then draws the positive sloped line (turns 22-25), indicating that she was paying attention to the reasoning Lisa provided. Later, Gina may recall how Lisa reasoned through this problem in determining her confidence in her ability to draw a similar velocitytime graph.

\section{References to vicarious learning opportunities are abundant}

As described in Sec. III, we begin the post hoc interviews by watching an 8-minute episode that included the segment presented in Table I. We then asked each participant if they noticed anything particular in the episode, and if not, discussed a set of preselected clips of about 30 seconds. In this section we will show that both Lisa and Jessica refer to events previously identified as vicarious learning opportunities as impacting their confidence in their capability.

Of the three participants, only Lisa commented on specifics of the session without prompting, and we present her ideas about the salience of the event for self-efficacy first. After Lisa watches the full 8-minute episode she mentions how the comments of the other students impact her confidence in her answers. Then, she identifies a particular event within the episode that made her feel not certain. After watching the video of that event again, she identifies the specific moments in the event that impacted her confidence in her capability.

Initially, Lisa watches the full 8-minute episode and the interviewer asks if she has any initial impressions. In response, Lisa outlines the role she plays as "getting everyone started." She immediately follows this statement, however, with one about the influence of the problem-solving events on her self-efficacy. Lisa says,

I think Gina, every time we [Lisa and Jessica] would say something, she was kind of like, 'Wait, wait, wait. Maybe it could be this, but.' So everyone was just getting confused, 'cause just when you thought you had the right thing, then someone is contradicting you, and so you think, "Maybe it's not right.'

We see in this statement from Lisa that comments from the other students make her think that her answer might not be right. The interviewer, in the session, follows up on Lisa's statement by asking if there was a particular instance in the episode that made Lisa feel this way.

Lisa reflects upon the episode and identifies a particular event where another student's comment makes her feel uncertain about her answer. When the interviewer asks Lisa if any particular event made her feel like someone was contradicting her, Lisa identifies turns 9-11 of Table I where Gina attempts to draw a velocity-time graph. In this clip, Gina draws two possible lines for the velocity-time graph: one with a positive slope and the other with a negative slope. The interviewer and Lisa watch this short clip again together.

After reviewing the clip, Lisa describes again how the other student's comment impacted her certainty. While watching the clip, Lisa breaks in at turn 9 and says, "So she draws it up, and then she does it, "maybe it could be this way." Afterwards Lisa reasons aloud why the two lines could not both be right. Then, the interviewer again asks her about what made her unsure in this clip. Lisa responds with,

Yeah, the fact that she even brought it up. So I thought, 'Wait, maybe.' I didn't just want to say, 'No, no, no, it's not that way.' Because it was a new concept. So I just wanted to make sure beforehand. And the fact that Jessica agreed, just like, 'OK, maybe it is this way.'

In Lisa's dialogue we notice two things. First, her confidence in her capability to draw a velocity-time graph was shaken. We see evidence of this by pairing her earlier comment of, "cause just when you thought you had the 
right thing, then someone is contradicting you, and so you think, "Maybe it's not right," with her statement here that she did not want to just say that Gina's answer was wrong. We can see in these statements that Lisa's confidence in her ability to judge her own answer has become unsettled. Second, the moment Lisa identifies becoming unsure, she is focused on the performance of Gina. We conclude, then, that it is the vicarious learning experience of watching Gina draw the velocity-time graph that impacted Lisa's self-efficacy. Earlier, when analyzing the problem-solving session, we identified the short clip in turns 9-11 as presenting a vicarious learning opportunity to Lisa. The evidence in the post hoc session indicates the VLO we identified was taken up and impacted Lisa's confidence in her ability to draw the velocity-time graph.

Jessica provides further evidence of a vicarious learning opportunity being taken up to impact her self-efficacy in this series of events. In this case, she did not identify the segment in Table I on her own, but it was instead shown to her as part of the six clips shown to all of the participants. Immediately after watching the clip (ending at turn 17), where Gina proposed that either of the two lines could be correct for the velocity-time graph, Jessica responds to the video with, "There I was doubting myself. In terms of umm the slope." The interviewer asks if Jessica's laughter at this point in the episode (turn 15) holds any meaning, and Jessica answers,

I don't think it means anything really. It's just sort of like, I'm just thinking. And, you know, they brought something up, and I'm like, 'OK, I don't know what to say.' I'm not really sure of myself at the moment.

Again, in Jessica's response to this video, we see a discussion of her confidence in her capability as a direct result of Gina suggesting the possibility of the two lines for the velocity-time graph. Combining Jessica and Lisa's post hoc interview comments, then, we see that in this case the vicarious learning opportunities we identified for Lisa and Jessica in the problem-solving session were indeed taken up and impacted their self-efficacy through the vicarious learning experience they gained from Gina.

\section{B. Social persuasion opportunities}

\section{Identifying and characterizing social persuasion opportunities}

As described in the literature review, researchers have had mixed results in investigating social persuasion experiences. We theorize that this may be because the messages one receives about performance and capability are often difficult to articulate. In evaluating this episode, we find that the events that can be characterized as social persuasion opportunities (SPO) are often subtle interactions. In particular, gaze direction, laughter, and interruptions all represent opportunities to communicate messages between individuals. To this end, the transcript separates the verbal communication and the nonverbal actions to aid in attending to these interactions in the discussion of SPOs.

We return to the segment in Table I, described in the previous section, which depicts Gina drawing a velocitytime graph for the car. This time we focus our attention particularly on the nonverbal behaviors that take place within this series of events, described within the first column in the transcript. We see a sequence of two events that provide an opportunity for social persuasion for Jessica. Gina has the marker in her hand and draws two different representations for the velocity on the velocitytime graph (turns 1-11). During this process, she pauses twice and turns her head to look at Jessica and ask, “Agree?" (turn 3), and “...right?” (turn 11). In turning to look at Jessica for evaluation of her performance, Gina communicates to Jessica that she believes in Jessica's ability to evaluate the answer she has proposed. As such, Jessica may interpret this experience and evaluate her confidence in her capability using this information; thus, we classify the experience as a SPO for Jessica.

When we extend this segment we also see a social persuasion opportunity unfolding for Gina in the final lines of the segment (turns 23-33). In turns 26-28, Gina makes a bid for a shift in activity by asking what the equation for the area under the curve of the velocity-time graph is. Lisa responds in turn 29 with, "It's a triangle." Gina reassures her that she knows and starts to ask a slightly different question in turns 30-31. Jessica attempts to finish Gina's sentence (turn 30), but Lisa breaks in with, "She's confusing herself," in turns 31 and 32, in reference to Gina's request. Gina restates her question in turn 33 as, "What's the equation for displacement?" We see the interruption and commentary from Lisa on Gina's incomplete work as an opportunity for a social persuasion experience for Gina. She may remember Lisa's interruption later and judge her ability to write the expression for displacement from an area under the curve based upon this experience.

\section{Students articulate the impact of social persuasion opportunities}

Gina's post hoc interview did not yield much information about self-efficacy until she finished watching the entire episode and all six preselected clips. At this point in the interview, the interviewer tells Gina that in many cases during the problem-solving process they had just watched, Gina was correct in the direction she wanted to lead the group. The interviewer then asks Gina why she often did not proceed in the direction proposed. In response, Gina refers to turns 23-33 specifically.

Recall that, after Lisa and Jessica correct Gina's velocity-time graph with the conclusion that the line must have a positive slope, Gina (turns 23 and 24) says, "But it would be like...this, no we're assuming." When she says these words, Gina mimes a velocity-time line with a positive slope, but below the $x$ axis. Gina decides they are 
assuming the velocity is positive and draws the line above the $x$ axis. Then she attempts to write an expression for the displacement using the area under the velocity-time graph. When she asks for help in turns 28-33, Lisa interrupts and comments, "She's confusing herself."

When we originally analyzed this segment, we concluded Gina had an opportunity for a social persuasion experience in turns 31 and 32, when Lisa interrupts her. When Gina comments on these two clips in the post hoc interview she confirms this opportunity impacted her self-efficacy,

And then the fact that she [Lisa] was like, "She's totally confusing herself." Maybe that made me feel, like I wasn't doing the right thing [looks down at the table, and shakes her head slightly].

In Gina's reaction to the problem-solving session, we see her focus on Lisa's interruption (in turn 32). She evaluates the entire event as, "That made me feel, like I wasn't doing the right thing." We see evidence in Gina's statement that the interrupting comment from Lisa impacted her confidence in her ability to move forward. The message from Lisa is not a direct comment on Gina's ability, but rather an indirect message that Gina interpreted. The event Gina identifies aligns with what we interpreted as a SPO, thus demonstrating that even indirect messages as characterized by SPOs can be taken up and impact self-efficacy.

\section{Mastery experience opportunities \\ 1. Identifying and characterizing mastery experience opportunities}

Mastery experience opportunities (MEOs) are often the easiest types of SEOs to observe unfolding. We characterize MEOs by showing evidence that a task is completed and that someone offers an evaluation of that task (see Table II for an example). A person could offer an evaluation in different forms, by verbally suggesting the product is good or bad, using gestures such as nodding the head to indicate satisfaction or dissatisfaction, or moving forward to the next step in the process that relies on the previous task being completed correctly.

In the segment in Table I, we see several MEOs unfolding as the students work through representing a velocitytime graph. When Gina turns to the board, we see her focus on drawing the velocity curve on the graph. In turns $1-22$, a series of MEOs for Gina occur. Initially, Gina proposes that the graph looks somewhat curved. Jessica shakes her head, indicating no (in turn 4) and corrects Gina, providing Gina with an opportunity for a mastery experience for drawing velocity-time graphs. Gina again attempts to draw the line, but proposes that there are actually two possibilities (one with a negative slope below the $x$ axis or one with a positive slope above the $x$ axis). Again, Lisa and Gina evaluate this proposal by comparing the line with the information from the acceleration-time graph. In turns 19-22, Lisa points out that the line must have a positive slope, and thus only one of the lines is a possibility. Gina may reflect upon any one of these events and find that they have influenced her confidence in her ability to correctly represent the curve on a velocity-time graph. As such, any one of these events may be interpreted as a mastery experience opportunity for Gina.

\section{Mastery experiences are de-emphasized through a focus on opportunities}

When examining the post hoc interviews, we find no evidence of the mastery experience opportunities identified in the segment in Table I being taken up by the participants. This result is initially surprising; in reviewing the literature, mastery experiences are often viewed as the predominant source of self-efficacy. We propose that the lack of emphasis on mastery experiences in this analysis is an artifact of the methodology we use. Characterizing opportunities to influence self-efficacy in the moment and using video to recall the event allows the role of others to become clear, and thus places less emphasis on the performances of a single individual. As a result, the methodology de-emphasizes MEOs while highlighting the role of VLOs and SPOs.

We believe that providing evidence that a portion of the identified SEOs were taken up and impacted self-efficacy validates the method, and a lack of evidence that all were taken up should not concern us unduly. We note an absence of evidence that all of the opportunities we have identified in this short clip are taken up, regardless of the source of self-efficacy. We contend that the lack of reference to an event does not mean that self-efficacy was not impacted in that moment. Rather, it suggests that the moment does not stand out from others when reviewing the problem-solving session. This method allows us to compare moments that students notice to those that they do not notice, thus providing a window into which moments may be the most salient opportunities to impact self-efficacy.

\section{DISCUSSION}

In this paper we have demonstrated that opportunities for influencing self-efficacy can be observed in actions as they are occurring. Using a theoretical understanding of what characterizes the various hypothesized sources of self-efficacy, we are able to observe three of the four sources of self-efficacy unfolding in real time. Initially we had hoped to observe physiological state opportunities (PSOs), but we found it difficult to infer information about the current excitement or anxiety of the participants through the video. This may have been partially because the majority of the time we could not see the faces of the students, and thus could not infer information from facial expressions. Nevertheless, we demonstrated our ability to characterize the other three sources, MEOs, VLOs, SPOs, in the present-tense moment of the experience occurring. 
The utility in understanding the sources of self-efficacy as opportunities in the present moment lies in the implications it holds for application. Understanding the development of self-efficacy only through the way participants recall events does not allow researchers or instructors to infer how to make those events occur. Bandura [7] notes, "Recall involves a process of reconstruction rather than simply retrieval of events" (p. 90). Considering selfefficacy only from these reconstructed recollections means that it may be difficult to ascertain the series of events that actually occurred and which then led to the particular reconstruction. Looking at self-efficacy experiences from the past and opportunities for self-efficacy experiences in the present through video analysis may allow researchers to make connections across time and hypothesize how the interpretation of an event affects confidence in capability as well as how to construct these events.

It also seems relevant that the vicarious learning opportunities and social persuasion opportunities we have characterized in this paper are subtle events, yet they had a direct influence on student self-efficacy. In typical studies where participants are asked to recall events that influenced their perception of capability, the subtle nature of these opportunities may be washed out by the relative abundance of opportunities for mastery experiences. When analyzing these data for MEOs, VLOs, and SPOs, we see that many of these opportunities occur simultaneously. We might expect that when students articulate events purely from memory, the salient features they mention may focus primarily on the MEOs as those are the moments that focus on their own actions. Alternatively, when we provide students with a video playback of the experience, we see a focus on VLOs and SPOs. We believe that these subtle events do impact student self-efficacy, but they are not necessarily verbalized when students are asked to recall what influenced confidence in capability. The difference in prominence in memory may be the reason why mastery experiences dominate much of the research literature on sources of self-efficacy $[24,30,32]$. The difference in saliency may be the reason why, when participants are interviewed at length, sources such as vicarious learning and social persuasion become more prevalent. Ample time for reflection on events or video evidence of the event may be needed to recall the more subtle opportunities for social persuasion and vicarious learning experiences.

Bandura [7] hypothesized that the way the sources of self-efficacy interact with one another to instill a sense of confidence in capability would be a complex and messy picture to untangle. In analyzing the present tense for opportunities for self-efficacy, we are able to see multiple opportunities for influence on self-efficacy within a single event. Furthermore, as evidenced by the impact on Lisa, Jessica, and Gina of Gina's drawing two velocity-time graphs, the influence of a single event may have an impact on multiple participants in a single instant in time. The method we have presented of describing self-efficacy opportunities using video as a stand-in for real time attends to the complex nature of the development of self-efficacy and provides a way to begin untangling the sources and participants from one another. This method serves to begin establishing an understanding of how the sources of selfefficacy interact with each other and can be interpreted either as a single event in the past or as two separate incidents that become intertwined when evaluating confidence in ability for a similar task at a later point.

Because of the complexity of the development of selfefficacy, we do not consider it appropriate to provide a prescriptive method to be applied by a series of explicit codes that correspond to MEOs, VLOs, and SPOs that could be universally applied by independent researchers. The complex interaction of the sources of self-efficacy does not lend itself to the simple reduction of individual phrases and gestures. Instead, we imagine understanding the development of self-efficacy in the moment lends itself to analyses which support the documentation of complex interactions, such as microanalysis [55]. However, we expect that independent researchers could go through a similar process as the one described in this paper and would come to see the identified self-efficacy opportunities. We see this work contributing toward a method that uses interaction analyses in video to document and characterize the ways in which particular events may provide opportunities to influence self-efficacy. These analyses would add to the survey and interview methodologies by providing frameworks for analyzing the development of self-efficacy in video in real time.

\section{CONCLUSION AND IMPLICATIONS}

Analysis of a problem-solving episode from a group of three students has revealed that it is possible to characterize opportunities for self-efficacy to be influenced without asking the participants to reflect on past events, and correlation of these opportunities with the impact of self-efficacy in the post hoc interviews suggests that these characterizations are valid. We present these results as a first phase in developing a methodology for examining the development of self-efficacy in real time. These results could be extended to include additional student groups and institutions; however, this work justifies further pursuit of characterizing self-efficacy opportunities in the moment. These results may be particularly relevant to researchers and teachers who are attempting to design events to influence self-efficacy. In relying solely on recollection of events, subtle influences such as those from vicarious learning opportunities and social persuasion opportunities may be washed out and result in the appearance that performance accomplishments dominate evaluations of academic capability for students. 
Further, we have demonstrated we can obtain new information on the development of self-efficacy by using video to examine events as they occur and have students reflect on these events. We propose that an exploration of self-efficacy experience opportunities would aid an investigation into the development of self-efficacy, particularly when combined with recollected self-efficacy experiences and measures of changing self-efficacy. With the understanding of how various learning environments construct SEOs, how various students interpret the opportunities, and how these interpretations influence self-efficacy, we can begin to design events that should impact self-efficacy in science in ways that will lead to increased success and persistence in science.

\section{ACKNOWLEDGMENTS}

This paper is based upon work supported by the National Science Foundation under Grant No. 0802184. The authors would like to thank the students who participated in this study, Idaykis Rodriguez for valuable discussions about this work, and the FIU Physics Education Research Group for their insight.
[1] H. B. Carlone and A. Johnson, Understanding the science experiences of successful women of color: Science identity as an analytic lens, J. Res. Sci. Teach. 44, 1187 (2007).

[2] Z. Hazari, G. Sonnert, P. M. Sadler, and M. C. Shanahan, Connecting high school physics experiences, outcome expectations, physics identity, and physics career choice: A gender study, J. Res. Sci. Teach. 47, 978 (2010).

[3] K. K. Perkins, W. K. Adams, S. J. Pollock, N.D. Finkelstein, and C. E. Wieman, Correlating student beliefs with student learning using the Colorado learning attitudes about science survey, in Proceedings of the 2004 Physics Education Research Conference, Sacramento, CA, 2004, edited by J. Marx, P. Heron, and S. Franklin (AIP, Melville, NY, 2004), p. 61.

[4] L.E. Kost-Smith, S. J. Pollock, and N. D. Finkelstein, Gender disparities in second-semester college physics: The incremental effects of a "smog of bias," Phys. Rev. ST Phys. Educ. Res. 6, 020112 (2010).

[5] A. Miyake, L. E. Kost-Smith, N. D. Finkelstein, S. J. Pollock, G. L. Cohen, and T. A. Ito, Reducing the gender achievement gap in college science: A classroom study of values affirmation, Science 330, 1234 (2010).

[6] L.E. Kost, S. J. Pollock, and N.D. Finkelstein, Characterizing the gender gap in introductory physics, Phys. Rev. ST Phys. Educ. Res. 5, 010101 (2009).

[7] A. Bandura, Self-Efficacy: The Exercise of Control, edited by S.F. Brennan and C. Hastings (W.H. Freeman and Company, New York, 1997).

[8] S. Andrew, Self-efficacy as a predictor of academic performance in science, J. Adv. Nurs. 27, 596 (1998).

[9] R. W. Lent, S.D. Brown, and K. C. Larkin, Relation of self-efficacy expectations to academic achievement and persistence, J. Counsel. Psychol. 31, 356 (1984).

[10] R. W. Lent, S. D. Brown, and K. C. Larkin, Comparison of three theoretically derived variables in predicting career and academic behavior: Self-efficacy, interest congruence, and consequence thinking, J. Counsel. Psychol. 34, 293 (1987).

[11] K. D. Multon, S. D. Brown, and R. W. Lent, Relation of self-efficacy beliefs to academic outcomes: A metaanalytic investigation, J. Counsel. Psychol. 38, 30 (1991).
[12] J. Pietsch, R. Walker, and E. Chapman, The relationship among self-concept, self-efficacy, and performance in mathematics during secondary school, J. Educ. Psychol. 95, 589 (2003).

[13] J. Dalgety and R. K. Coll, Exploring first-year science students' chemistry self-efficacy, Int. J. Sci. Math. Educ. 4, 97 (2006).

[14] R. W. Lent, S. D. Brown, and K. C. Larkin, Self-efficacy in the prediction of academic performance and perceived career options, J. Counsel. Psychol. 33, 265 (1986).

[15] S. D. Brown, R. W. Lent, and K. C. Larkin, Self-efficacy as a moderator of scholastic aptitude-academic performance relationships, J. Vocat. Behav. 35, 64 (1989).

[16] D. A. Luzzo, P. Hasper, K. A. Albert, M. A. Bibby, and E. A. Martinelli, Jr., Effects of self-efficacy-enhancing interventions on the math/science self-efficacy and career interests, goals, and actions of career undecided college students, J. Counsel. Psychol. 46, 233 (1999).

[17] A. M. L. Cavallo, W. H. Potter, and M. Rozman, Gender differences in learning constructs, shifts in learning constructs, and their relationship to course achievement in a structured inquiry, yearlong college physics course for life science majors, School Sci. Math. 104, 288 (2004).

[18] L. E. Kost, S. J. Pollock, and N. D. Finkelstein, Unpacking gender differences in students' perceived experiences in introductory physics, in Proceedings of the 2009 Physics Education Research Conference, Ann Arbor, MI, edited by M. Sabella, C. Henderson, and C. Singh (AIP, Melville, NY, 2009), p. 177.

[19] K. A. Shaw, The development of a physics self-efficacy instrument for use in the introductory classroom, in Proceedings of the 2003 Physics Education Research Conference, Madison, 2003, edited by J. Marx, S. Franklin, and K. Cummings (AIP, New York, 2003), p. 137.

[20] V. Sawtelle, E. Brewe, and L. H. Kramer, Positive impacts of modeling instruction on selfefficacy, in Proceedings of the 2010 Physics Education Research Conference, Portland, OR (AIP, Melville, NY, 2010), p. 289.

[21] A. Bandura, Self-efficacy: Toward a unifying theory of behavioral change, Psychol. Rev. 84, 191 (1977). 
[22] K. O. Moe and A.M. Zeiss, Measuring self-efficacy expectations for social skills: A methodological inquiry, Cognit. Ther. Res. 6, 191 (1982).

[23] A. Bandura, Social cognitive theory: An agentic perspective, Annu. Rev. Psychol. 52, 1 (2001).

[24] S. L. Britner, Motivation in high school science students: A comparison of gender differences in life, physical, and earth science classes, J. Res. Sci. Teach. 45, 955 (2008).

[25] S. Lau and R. W. Roeser, Cognitive abilities and motivational processes in high school students' situational engagement and achievement in science, Educ. Assess. 8, 139 (2002).

[26] V. Sawtelle, E. Brewe, and L.H. Kramer, Exploring the relationship between self-efficacy and retention in introductory physics, J. Res. Sci. Teach. (to be published).

[27] R. M. Schwartz and J. M. Gottman, Toward a task analysis of assertive behavior, J. Consult. Clin. Psychol. 44, 910 (1976).

[28] R. W. Lent, F. G. Lopez, S. D. Brown, and P. A. Gore, Jr., Latent structure of the sources of mathematics selfefficacy, J. Vocat. Behav. 49, 292 (1996).

[29] M. A. Hutchison, D. K. Follman, M. Sumpter, and G. M. Bodner, Factors influencing the self-efficacy beliefs of firstyear engineering students, J. Eng. Educ. 95, 39 (2006).

[30] R. W. Lent, S. D. Brown, M. R. Gover, and S. K. Nijjer, Cognitive assessment of the sources of mathematics selfefficacy: A thought-listing analysis, J. Career Assess. 4, 33 (1996).

[31] R. W. Lent, F. G. Lopez, and K. J. Bieschke, Mathematics self-efficacy: Sources and relation to science-based career choice, J. Counsel. Psychol. 38, 424 (1991).

[32] T. Matsui, K. Matsui, and R. Ohnishi, Mechanisms underlying math self-efficacy learning of college students, J. Vocat. Behav. 37, 225 (1990).

[33] K. A. Gainor and R. W. Lent, Social cognitive expectations and racial identity attitudes in predicting the math choice intentions of Black college students, J. Counsel. Psychol. 45, 403 (1998).

[34] F. G. Lopez and R. W. Lent, Sources of mathematics selfefficacy in high school students, Career Dev. Q. 41, 3 (1992).

[35] E. L. Usher and F. Pajares, Sources of academic and selfregulatory efficacy beliefs of entering middle school students, Contemp. Educ. Psychol. 31, 125 (2006).

[36] M. Hutchison-Green, D. Follman, and G. Bodner, Providing a voice: Qualitative investigation of the impact of a first-year engineering experience on students' efficacy beliefs, J. Eng. Educ. 97, 177 (2008).

[37] D. Palmer, Sources of self-efficacy in a science methods course for primary teacher education students, Res. Sci. Educ. 36, 337 (2006).

[38] A. L. Zeldin and F. Pajares, Against the odds: Self-efficacy beliefs of women in mathematical, scientific, and technological careers, Am. Educ. Res. J. 37, 215 (2000).
[39] A. L. Zeldin, S. L. Britner, and F. Pajares, A comparative study of the self-efficacy beliefs of successful men and women in mathematics, science, and technology careers, J. Res. Sci. Teach. 45, 1036 (2008).

[40] E. L. Usher and F. Pajares, Sources of self-efficacy in school: Critical review of the literature and future directions, Rev. Educ. Res. 78, 751 (2008).

[41] F. Pajares, M. J. Johnson, and E. L. Usher, Sources of writing self-efficacy beliefs of elementary, middle, and high school students, Res. Teach. Engl. 42, 104 (2007).

[42] R. M. Klassen, A cross-cultural investigation of the efficacy beliefs of South Asian immigrant and Anglo Canadian nonimmigrant early adolescents, J. Educ. Psychol. 96, 731 (2004).

[43] G. Hackett and N. E. Betz, An exploration of the mathematics self-efficacy/mathematics performance correspondence, J. Res. Math. Educ. 20, 261 (1989).

[44] G. Hackett and N. E. Betz, A self-efficacy approach to the career development of women, J. Vocat. Behav. 18, 326 (1981).

[45] F. Erickson, Ethnographic Microanalysis of Interaction (Academic, San Diego, CA, 1992), p. 201.

[46] D. Ratcliff, Video Methods in Qualitative Research (American Psychological Association, Washington, DC, 2003), p. 113.

[47] E. Brewe, V. Sawtelle, L. H. Kramer, G. E. O'Brien, I. Rodriguez, and P. Pamelá, Toward equity through participation in Modeling Instruction in introductory university physics, Phys. Rev. ST Phys. Educ. Res. 6, 010106 (2010).

[48] D. Hestenes, M. Wells, and G. Swackhamer, Force concept inventory, Phys. Teach. 30, 141 (1992).

[49] E. Brewe, L. Kramer, and G. O'Brien, Modeling Instruction: Positive attitudinal shifts in introductory physics measured with CLASS, Phys. Rev. ST Phys. Educ. Res. 5, 013102 (2009).

[50] D. Hestenes, Toward a modeling theory of physics instruction, Am. J. Phys. 55, 440 (1987).

[51] E. Brewe, Modeling theory applied: Modeling Instruction in introductory physics, Am. J. Phys. 76, 1155 (2008).

[52] M. Wells, D. Hestenes, and G. Swackhamer, A modeling method for high school physics instruction, Am. J. Phys. 63, 606 (1995).

[53] D. M. Desbien, Ph.D. thesis, Arizona State University, 2002.

[54] M.Q. Patton, Qualitative Research and Evaluation Methods (Sage Publications, Thousand Oaks, CA, 2002).

[55] S. J. Derry, R. D. Pea, B. Barron, R. A. Engle, F. Erickson, R. Goldman, R. Hall, T. Koschmann, J. L. Lemke, and M. G. Sherin, Conducting video research in the learning sciences: Guidance on selection, analysis, technology, and ethics, J. Learn. Sci. 19, 3 (2010).

[56] E. Ochs, Transcription as Theory (Academic, New York, 1979), p. 43.

[57] J. W. Creswell and D. L. Miller, Determining validity in qualitative inquiry, Theory Into Practice 39, 124 (2000). 